\title{
Stereotactic laser ablation of high-grade gliomas
}

\author{
Ammar H. Hawasli, M.D., Ph.D., ${ }^{1}$ Albert H. Kim, M.D., Ph.D., ${ }^{1-3}$ \\ Gavin P. Dunn, M.D., Ph.D., ${ }^{1,4,6}$ David D. Tran, M.D., Ph.D., 5 \\ and Eric C. LeuthardT, M.D. ${ }^{1,7-9}$ \\ Departments of ${ }^{1}$ Neurosurgery, ${ }^{2}$ Neurology, ${ }^{3}$ Developmental Biology, and ${ }^{4}$ Pathology and Immunology; \\ ${ }^{5}$ Neuro-Oncology Program, Division of Oncology, Department of Medicine; ${ }^{6}$ Center for Human Immunology \\ and Immunotherapy Programs; ${ }^{7}$ Center for Innovation in Neuroscience and Technology; and Departments of \\ ${ }^{8}$ Biomedical Engineering and ${ }^{9}$ Mechanical Engineering and Material Sciences, Washington University, \\ St. Louis, Missouri
}

Evolving research has demonstrated that surgical cytoreduction of a high-grade glial neoplasm is an important factor in improving the prognosis of these difficult tumors. Recent advances in intraoperative imaging have spurred the use of stereotactic laser ablation (laser interstitial thermal therapy [LITT]) for intracranial lesions. Among other targets, laser ablation has been used in the focal treatment of high-grade gliomas (HGGs). The revived application of laser ablation for gliomas parallels major advancements in intraoperative adjuvants and groundbreaking molecular advances in neuro-oncology. The authors review the research on stereotactic LITT for the treatment of HGGs and provide a potential management algorithm for HGGs that incorporates LITT in clinical practice. (http://thejns.org/doi/abs/10.3171/2014.9.FOCUS14471)

\section{Key Words - laser ablation - laser interstitial thermal therapy $\quad$ glioma $\bullet$ glioblastoma $\quad$ minimally invasive surgery}

$\mathrm{G}$ LIOMAS account for $28 \%$ of the nearly 70,000 primary brain tumors diagnosed in the US annually. ${ }^{14,18,53}$ Most gliomas are classified as high-grade gliomas (HGGs): anaplastic gliomas (WHO Grade III) and glioblastomas multiforme ([GBMs], WHO Grade IV). High-grade gliomas represent $80 \%$ of malignant primary brain tumors..$^{14,18,53}$ In spite of intensive research over the past several decades, overall prognosis for HGGs remains poor. ${ }^{72}$ Although we have learned a great deal about the molecular and cellular biology of malignant glioma over the last decade, we have much work to do to translate our scientific understanding into improved therapeutic approaches. ${ }^{10,11,50,52,72,77}$ More aggressive resections have been shown to play a role in improving clinical outcomes. ${ }^{11,12,37,42,61}$ Although extent of resection is important, this is always counterbalanced against the potential for functional impairments associated with surgery, which can also reduce the overall prognosis..$^{25,37,43} \mathrm{New}$ technologies that enable an improved balance between tumor cytoreduction and the need to preserve relevant brain function are emerging. Specifically, MRI-guided laser interstitial thermal therapy (LITT) is becoming an

\footnotetext{
Abbreviations used in this paper: $\mathrm{BBB}=$ blood-brain barrier; BCNU = carmustine; GBM = glioblastoma multiforme; GTR = gross-total resection; HGG = high-grade glioma; KPS = Karnofsky Performance Scale; LITT = laser interstitial thermal therapy.
}

important surgical tool for treatment of HGGs in several clinical contexts. In this work we review the technology, clinical experience with, and general indications for LITT, along with emerging applications of this approach.

\section{Stereotactic LITT}

Stereotactic LITT is a minimally invasive treatment for intracranial lesions. This method stems from similar minimally invasive ablation techniques pioneered by general surgeons. ${ }^{19,35,40,68}$ Stereotactic laser ablation produces high temperatures that lead to tissue coagulation, necrosis, and cellular apoptosis..$^{2-4,7,32,60,73}$ Research in animals has shown that ablation produces a histologically proven immediate disruption of the blood-brain barrier (BBB) and subsequent neovascularization, which can be

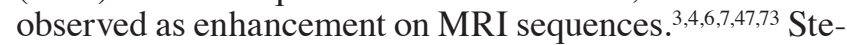
reotactic laser ablation techniques for intracranial lesions have historically been limited by the inability to monitor ablation progress or temperature intraoperatively. Online intraprocedural treatment monitoring is critical for stereotactic LITT to assess real-time tissue temperature and avoid treatment beyond the target zone. Fortunately, recent technological advances in intraoperative MRI now enable accurate intraoperative thermal monitoring. Intraprocedural repetitive measurements of T1-weighted 2D fast low-angle shot sequences or similar methodologies 
provide the temporally sensitive thermometry measurements necessary to create controlled and conformal lesions (Fig. 1A). ${ }^{28,32-34}$

Additionally, stereotactic laser ablation has been further streamlined by clinicians and industry innovators to make laser ablation an optimal and safe procedure. ${ }^{23,28,45,49}$ There are currently 2 frequently used stereotactic LITT technologies for intracranial ablations: Neuroblate (Monteris Medical) and Visualase. Although both technologies serve to provide the same ultimate results (i.e., target ablation), each has its own advantages. One version of Neuroblate has a side-firing probe that can be rotated, advanced, and retracted by an MRI-compatible driver for conformal treatments and a large radius of treatment, at the potential cost of treatment time (Fig. 1B). The standard Visualase system (Fig. 1C) and an alternative Neuroblate version use a diffuse-tip probe that generates a uniform ellipsoid ablation zone around the center of the probe. This method saves time at the expense of target conformality. Depending on whether it is a diffuse-tip probe or a sidefiring probe, the effective treatment radius ranges from approximately 1 to $2 \mathrm{~cm}$. Thus, because the probe can be moved back and forth along its implanted axis, the "treatment" column can be as large as $3 \mathrm{~cm}$ (or larger with the side-firing type). This impacts the size of lesions that can be treated. Tumors less than $3 \mathrm{~cm}$ in maximal diameter can be readily treated with single-trajectory LITT. As the tumor gets larger, or the anatomical dimensions become less globoid, treatment may require more than one trajectory. Also, as the size becomes greater than $3 \mathrm{~cm}$, it is important to consider the mass effect of the tumor, which can occasionally be transiently exacerbated by LITT. To date, LITT has been used to treat both primary and meta- static brain tumors, radiation necrosis, and epilepsy foci with varying degrees of success ${ }^{57}$ Here, we review the literature on the use of LITT for HGGs and discuss a possible role for this procedure in clinical settings for both newly diagnosed and recurrent HGGs.

\section{Treatment of Newly Diagnosed HGGs}

Anaplastic astrocytomas carry a 2-year survival rate of up to $50 \%{ }^{24}$ and have a strong tendency to progress to GBM in approximately 2 years. ${ }^{51}$ Glioblastoma multiforme accounts for the majority of adult brain tumors and, without treatment, the median overall survival in patients with GBM is reported to be 9 weeks. ${ }^{17}$ The current standard of care for newly diagnosed GBM with temozolomide and radiation therapy increases median survival to 14.6 months. ${ }^{72}$ The temozolomide and radiation combination therapy is well tolerated and increases 2-, 3-, and 5-year survival to $27.2 \%, 10.1 \%$, and $9.8 \%$, respectively. ${ }^{72}$ Cytoreduction by resection has also been shown to increase survival in patients with HGG compared with biopsy alone. Several retrospective studies have shown increased median survival with gross-total resection (GTR) of HGGs. ${ }^{12,37,42,61}$ This has been corroborated by a prospective study of 124 newly diagnosed patients with HGG, which demonstrated that GTR was associated with longer survival and better quality of life than biopsy alone. ${ }^{11}$

Surgical adjuvants such as intraoperative MRI ${ }^{15,29,36,66}$ and 5-aminolevulinic acid ${ }^{46,70,71}$ are associated with greater extent of HGG resection and improved progressionfree survival. Hence, the current standard treatment algorithm for newly diagnosed HGGs is GTR of the enhancing tumor, followed by temozolomide and radiation
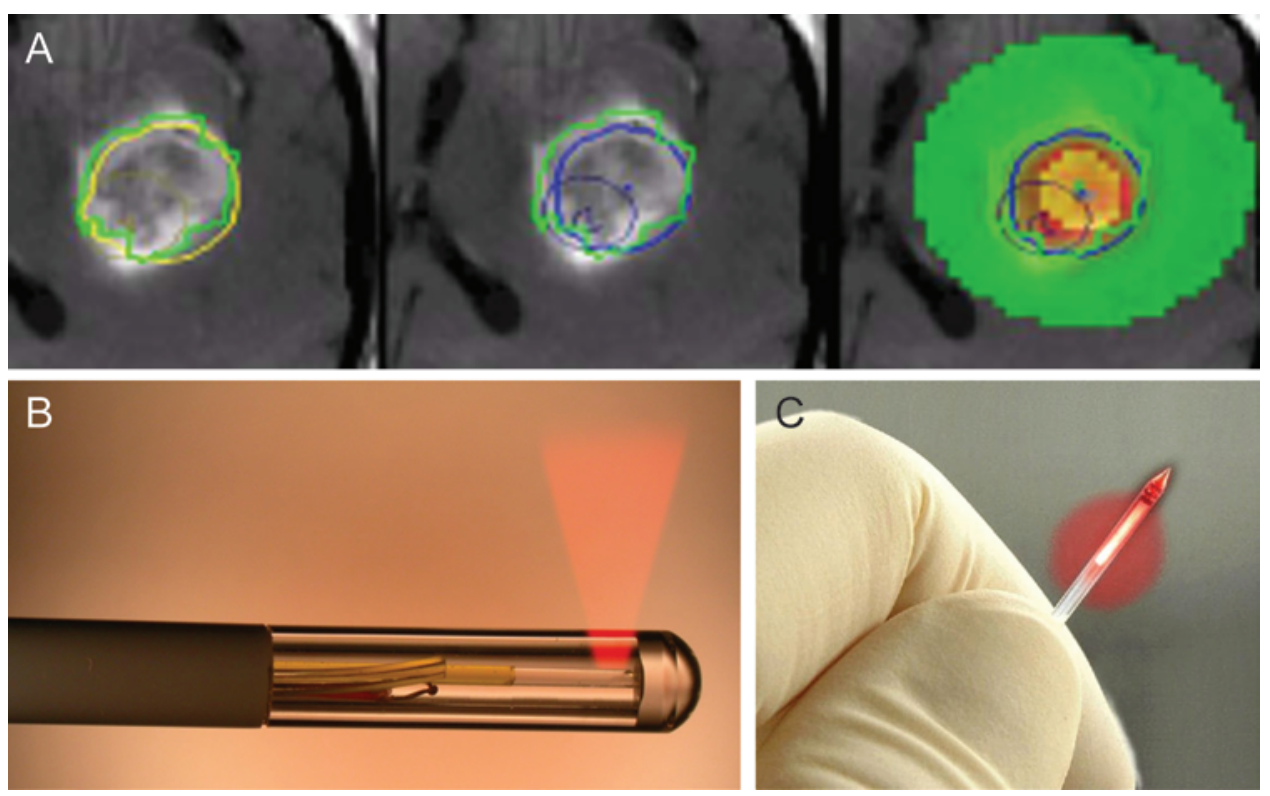

FIG. 1. Stereotactic laser ablation of brain tumors. A: Example of intraoperative thermometry monitoring during LITT of an insular brain tumor. In the left and center panels, green lines indicate target periphery. Yellow, blue, and black lines indicate the edge of low-, medium-, and high-dose margins. The right panel shows an example of cumulative temperature measurements during LITT. Reproduced with permission from Neurosurgery. Hawasli AH et al: Magnetic resonance imaging-guided focused laser interstitial thermal therapy for intracranial lesions: single-institution series. Neurosurgery 73(6):1007-1017, 2013. B: Image of Neuroblate probe with side-emitting laser.

C: Image of Visualase probe with uniform laser emission. 
therapies. ${ }^{52,77}$ Although chemoradiation therapy is generally well tolerated, surgery is not always a viable option. In certain circumstances, the patient may be too ill to tolerate a craniotomy for tumor resection. In other situations, the tumor may be in a location involving eloquent cortex or deep-seated structures, in which case resection would lead to significant neurological deficits. For these patients, current treatment typically includes biopsy for diagnosis followed by chemoradiation. ${ }^{52}$ Therefore, novel technologies such as LITT aimed at maximal local cytoreductive therapy would potentially have a significant impact on overall outcomes for these patients. The main treatment indication for the use of LITT in newly diagnosed HGG has been for patients with inoperable brain tumors or those who are not candidates for open surgery due to advanced age and/or medical comorbidities. Common tumor locations that are ideal for up-front LITT include deep gray matter regions (e.g., thalamus and basal ganglia), the corpus callosum, and the insula (Fig. 2A and $\mathrm{B})$-providing cytoreductive therapy while minimizing the morbidity of the surgical approach.

\section{Treatment of Recurrent HGGs}

In spite of maximal surgical and chemoradiation therapy, tumor progression is inevitable in the vast majority of patients with HGG. Survival for patients with recurrent HGGs remains poor, at 3-9 months. ${ }^{5,21}$ There is little consensus on the optimal management strategy for recurrent HGGs. Several retrospective Level of Evidence III-IV studies $^{74}$ support repeat tumor resections, as long as the patient's performance status is not low and preoperative

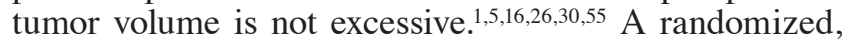
double-blind, placebo-controlled control trial also supported the implantation of carmustine (BCNU) wafers in tumor cavities after repeat operation. ${ }^{10}$ Although salvage temozolomide had previously been used for recurrent GBM, ${ }^{9,56,80}$ recent Level II evidence clinical studies in patients with recurrent GBM have demonstrated that salvage chemotherapy combining bevacizumab, an antiangiogenic agent, with cytotoxic drugs can extend progression-free survival and overall survival to 6.1 and 9.2 months, respectively. ${ }^{21,75,82}$ Finally, emerging agents that target tumorigenesis pathways, such as new angiogenesis inhibitors and other novel agents, show promise as therapeutic options. ${ }^{76}$ In select patients, salvage chemotherapy for recurrent HGGs is optimally preceded by repeat resection. 1,5,16,26,30,55,74,81 However, for a range of reasons, there are subsets of patients who are not ideal candidates for traditional open surgery, and many patients decline open surgery due to associated morbidity. For these patients, LITT has been considered a reasonable option for many reasons (Fig. 2C).

There are several advantages and arguments for the use of LITT in select patients with recurrent HGGs. First, recurrent lesions that are small, focal, and nodular are particularly amenable to a focal therapy. Given that recurrence is local in the majority of patients, LITT can target these areas focally. Second, reoperation in many patients with recurrent HGG can lead to more morbidity because of the patient's frailty and higher risk for wound heal-
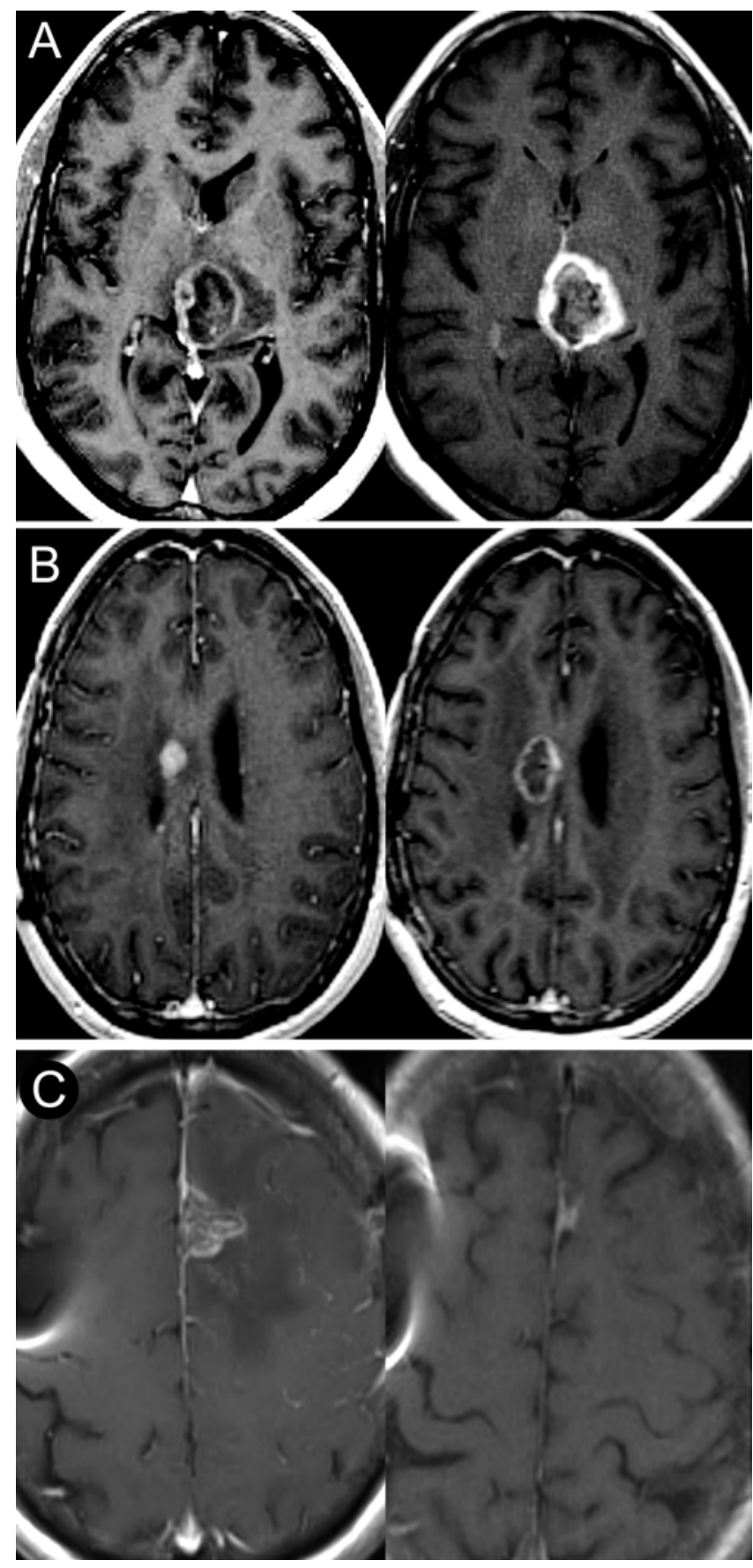

FIG. 2. Radiographic results after stereotactic laser ablation of brain tumors. A: Preoperative (left) and postoperative (right, 3 months post-LITT) T1-weighted axial MRI of brain obtained with Gd contrast showing thalamic GBM treated de novo with LITT. Postoperative image shows stable ring enhancement at the edge of treatment zone. Reproduced with permission from Neurosurgery. Hawasli AH et al: Magnetic resonance imaging-guided focused laser interstitial thermal therapy for intracranial lesions: single-institution series. Neurosurgery 73(6):10071017, 2013. B: Preoperative (left) and postoperative (right, 5 months post-LITT) T1-weighted axial MRI of brain obtained with Gd contrast showing GBM in right corpus callosum treated with LITT. C: Preoperative (left) and postoperative (right, 3 months post-LITT) T1-weighted axial MRI of brain obtained with Gd contrast showing treatment of recurrent frontal lobe GBM. 
ing complications after prior radiation and chemotherapy. Third, salvage chemotherapy may achieve better efficacy following maximal safe cytoreduction. Fourth, a cytoreductive approach provides the best option in tumors in which other therapies have been exhausted. Finally, LITT can be used repeatedly because there is no demonstrable dose toxicity (as with radiation) and the tumor does not develop resistance to LITT (as seen with chemotherapy).

\section{The Radiographic Effects of LITT}

Besides history taking and physical examination, neuroradiological imaging such as MRI is the primary method to assess responses to brain tumor therapies. Hence, during the past several decades, radiographic responses to LITT have been reported by numerous groups. Although radiographic responses to LITT for HGGs are described in detail below, it is important to understand the basic general observations after LITT for brain tumors. The first effect that is seen after LITT (within days of treatment) is central coagulation, which is observed as T1-weighted hyperintensity consistent with coagulated blood products in the center of the lesion (Fig. 3A and B). This often has a semiuniform "ground glass" appearance.
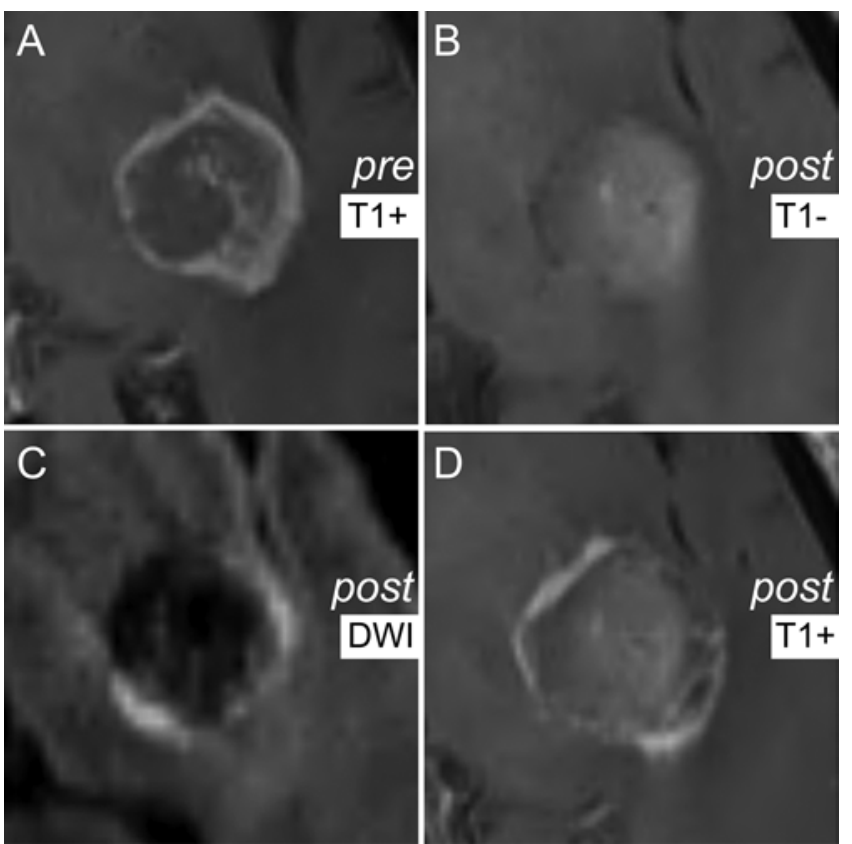

FIG. 3. Exemplar MRI studies showing immediate postoperative effects of LITT on brain tumors. A: Preoperative (pre) T1-weighted MRI study obtained with $\mathrm{Gd}(\mathrm{T} 1+)$ demonstrates an enhancing insular tumor. B: Postoperative (post) T1-weighted MRI study obtained without $\mathrm{Gd}(\mathrm{T} 1-)$ on the day after surgery shows isointensity within the tumor center representing coagulation products. C: Postoperative (post) diffusion-weighted imaging (DWI) MRI study shows diffusion restriction at the peripheral edge of the tumor. D: Postoperative (post) T1-weighted MRI study obtained with $\mathrm{Gd}(\mathrm{T} 1+)$ shows a new contrast-enhancing rim just outside the periphery of the tumor corresponding with the edge of the ablation zone. Reproduced with permission from Neurosurgery. Hawasli AH et al: Magnetic resonance imaging-guided focused laser interstitial thermal therapy for subinsular metastatic adenocarcinoma: technical case report. Neurosurgery 70 (2 Suppl Operative):332-338, 2012.
This may be observed on postoperative CT scans as central hyperdense blood products. Additionally, LITT often produces a rim of diffusion restriction at the edge of the treatment zone (Fig. 3C) and a peripheral rim of enhancement (Fig. 3D), which is thought to represent a degradation of the surrounding BBB. ${ }^{47,59,60,62}$ Subsequent effects vary depending on the tumor, the patient, and responses to LITT, which are described below.

\section{Methods}

A comprehensive search of the English literature was performed using PubMed (http://www.ncbi.nlm.nih. gov/pubmed) and Google Scholar (http://scholar.google. $\mathrm{com} /$ ). Clinical research articles on stereotactic laser ablation for brain tumors were selected and evaluated for possible inclusion in the review. Inclusion criteria for study selection were as follows: 1) human study; 2) use of stereotactic laser ablation for brain tumors; and 3) at least a portion of the cohort reported had HGGs (WHO Grade III or IV gliomas). The study results also had to provide a Level IV or better level of evidence. This included randomized, controlled trials; prospective cohort studies; case-controlled studies; retrospective cohort studies; case series; and case reports. Expert opinions, reviews without presentation of clinical data, and reports without HGGs were excluded. Each article was thoroughly reviewed for details on treatments and outcomes.

\section{Results}

\section{Article Selection}

The preliminary search for the use of laser therapy for brain tumors yielded 145 abstracts. After exclusion of nonhuman studies, expert opinions, and review articles lacking direct clinical data, 28 articles were identified. Each article was reviewed in detail and 10 were excluded for absence of HGGs, yielding a total of 18 eligible human clinical research publications on the use of laser ablation to treat HGGs (Table 1). The studies published between 1990 and 2014 included a total of 230 patients and were case series and case reports without control cohorts. Although some patients were probably reported in more than one manuscript, duplication in data used between clinical studies was not easily ascertainable and could not be confirmed.

\section{Treatment of HGGs With Stereotactic Laser Ablation}

In the 18 eligible studies reviewed, 174 HGGs were reported to have been treated with LITT. The WHO grade was reported in 15 studies (Table 1). Glioblastomas (WHO Grade IV) and anaplastic gliomas/oligodendrogliomas (WHO Grade III) accounted for 106 (66\%) and $55(34 \%)$ patients, respectively. The number of patients with newly diagnosed versus recurrent tumors was available in 12 of 18 studies. Fifty-three patients (34\%) were treated up front (de novo) for newly diagnosed HGGs, and 105 patients $(66 \%)$ were treated with salvage therapy for recurrent HGGs. Twelve manuscripts reported tumor locations: 39 (38\%), $16(16 \%)$, and $15(15 \%)$ of the 103 


\section{Laser ablation for gliomas}

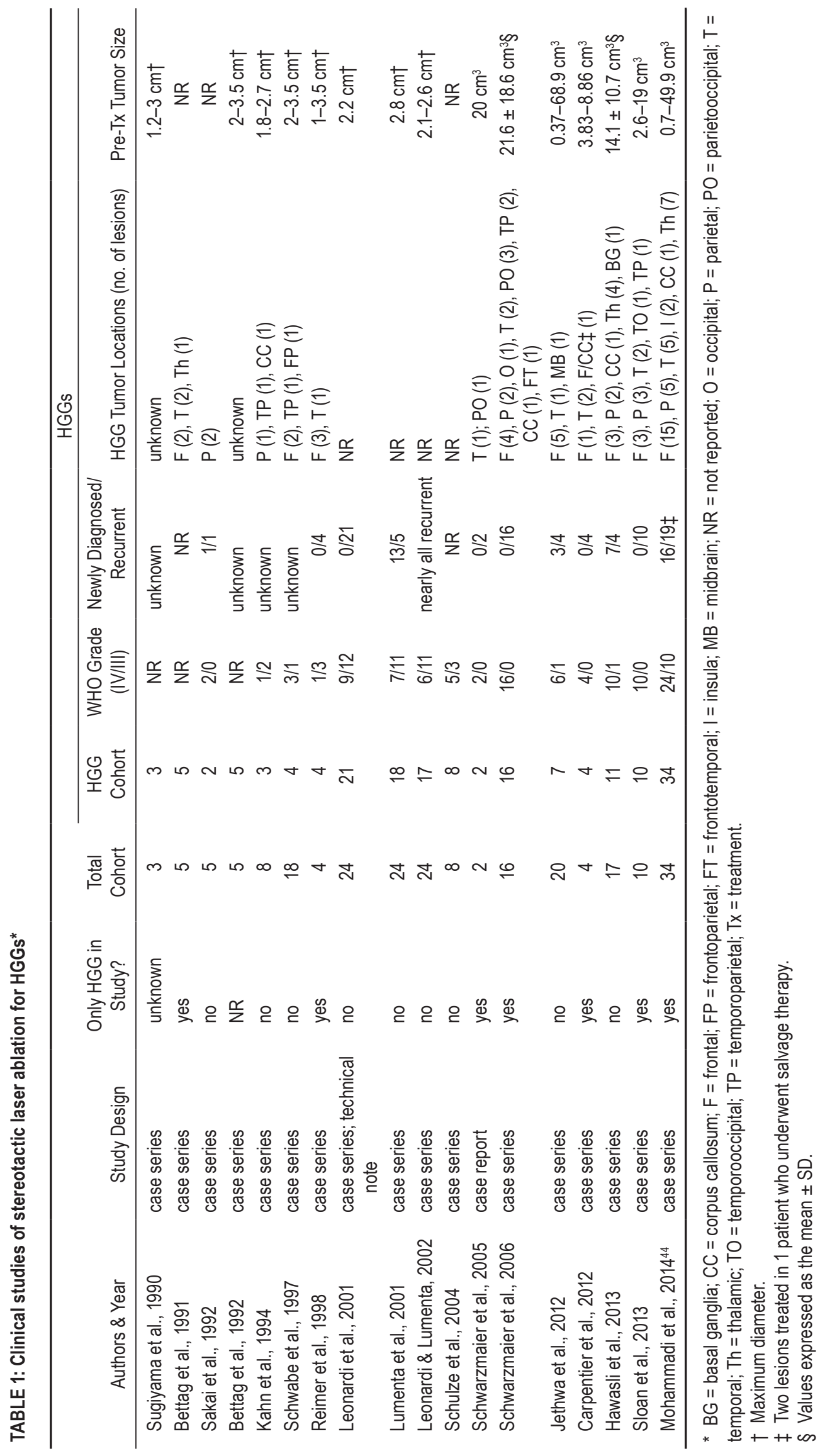


HGGs in which location was reported were located in the frontal, temporal, and parietal lobes, respectively. Twenty-one $(20 \%)$ of these 103 HGGs were located in difficult to access locations, including 12 in the thalamus (12\%), 5 in the corpus callosum (5\%), 2 in the insula (2\%), 1 in the basal ganglia $(1 \%)$, and 1 in the midbrain $(1 \%)$. Pretreatment tumor size measurements were either reported as maximum diameters or volumes in 11 studies. Maximum diameters ranged from 1 to $3.5 \mathrm{~cm}$ and volumes ranged from 0.37 to $68.9 \mathrm{~cm}^{3}$. Treatment times were reported as either laser times or total operative times (Table 2). Laser times ranged from 1.5 to 40 minutes and operative times ranged from 2 to 16 hours. Early publications subjectively reported that ablation covered the entire enhancing portion of the tumors. Recent reports have provided quantitative coverage data. Although thermal distribution data varied, recent authors reported treatment of tumor periphery at $42^{\circ} \mathrm{C}-45^{\circ} \mathrm{C}$. Although there is probably some patient duplication among studies and some variation in laser technologies, laser wattages, intraoperative temperature monitoring, and other therapies received during the studies, the cumulative data offered valuable information about the potential use of LITT for the management of HGGs.

\section{Radiographic Outcomes After Treatment of HGGs With Stereotactic Laser Ablation}

The radiographic outcomes after LITT for HGGs were reported in 16 of 18 studies (Tables 3 and 4). Not all reported patients who received LITT for HGG underwent follow-up imaging, and radiographic follow-up for each patient was difficult to assess. In 3 studies, only immediate radiographic outcomes were reported. Five studies reported the presence of central necrosis of the tumor after ablation in at least 53 patients, as demonstrated on T1and T2-weighted MRI sequences. Gadolinium enhancement of the tumor periphery shortly after LITT was re- ported in 4 studies and 47 patients with HGG. Ten articles reported decreases in HGG size after ablation in at least 51 patients. Reduced tumor size on neuroimaging was reported 0.5-10 months after LITT.7,13,62-65 Kahn et al. and Hawasli et al. reported $15 \%-87 \%$ and $67 \%$ decreases, respectively, in tumor size after LITT on follow-up imaging. ${ }^{27,32}$ At least 22 patients showed no recurrence during the study duration. Sakai et al. and Reimer et al. reported radiographic recurrences at 15,8 , and 6 months postLITT. ${ }^{58,60}$ Hawasli et al. reported radiographic recurrences in 5 of 11 patients at a mean of 6.2 months post-LITT. ${ }^{27}$ Mohammadi et al. reported radiographic progression in 23 patients with 5 central, 12 peripheral, and 6 distant recurrences. ${ }^{44}$ Hence, immediate radiographic analyses generally showed initial treatment effects including central tumor necrosis and peripheral enhancement. Despite reporting variability, several studies showed a reduction in HGG size, ranging from within days of LITT to within 33 months. These radiographic findings suggested that laser ablation is a potential treatment option for patients with HGGs.

\section{Clinical Outcomes After Treatment of All HGGs With Stereotactic Laser Ablation: Overall Analysis}

Clinical outcomes after LITT for all HGGs (both newly diagnosed and recurrent HGGs) were reported in 12 of 18 studies reviewed. Some studies reported individual times until cancer progression, time until death, and time until neurological deterioration. Other articles provided overall median or mean values for their cohorts. Individual results were reported in 6 studies. In these, tumor progression for all HGGs was reported at 2.615 months after LITT. Times until death due to tumor progression were reported at 4.1-23 months after LITT (Table 3). The median or mean clinical outcome statistics were reported on LITT for HGG in 6 manuscripts. In patients with HGG treated with LITT, overall median

TABLE 2: Treatment data on stereotactic laser ablation for HGGs

\begin{tabular}{|c|c|c|c|}
\hline Authors \& Year & Tx Times & Tumor Tx Coverage & Thermal Distribution \\
\hline Sugiyama et al., 1990 & $30-40 \mathrm{~min}^{*}$ & complete enhancement & $42.5-43.5^{\circ} \mathrm{C}$ at periphery \\
\hline Sakai et al., 1992 & NR & NR & $63^{\circ} \mathrm{C}$ at center; $43-33^{\circ} \mathrm{C}$ at periphery \\
\hline Kahn et al., 1994 & $10-30 \mathrm{~min}^{*}$ & complete enhancement & $43^{\circ} \mathrm{C}$ at periphery \\
\hline Reimer et al., 1998 & 4-33 $\min ^{*}$ & complete enhancement & NR \\
\hline Leonardi et al., 2001 & $2-27 \min ^{*}$ & 1.8- to 2.7-cm diameter & NR \\
\hline Lumenta et al., 2001 & $2-27 \min ^{*}$ & NR & NR \\
\hline Schulze et al., 2004 & 10-16 min;* mean 224 min† & NR & NR \\
\hline Jethwa et al., 2012 & $13.9 \pm 10.7 \min (1.83-35.9 \mathrm{~min})^{\star} \ddagger$ & $0.95-9.63 \mathrm{~cm}^{2}$ & NR \\
\hline Carpentier et al., 2012 & $93 \sec (30-180 \mathrm{sec})^{*}$ & $3.76 \mathrm{~cm}^{3}\left(1.8-8.9 \mathrm{~cm}^{3}\right)$ & $43-50^{\circ} \mathrm{C}$ of all enhancing tumor \\
\hline Hawasli et al., 2013 & $6 \pm 2$ hrst‡ & $45^{\circ} \mathrm{C}: 19.7 \mathrm{~cm}^{3} ; 52^{\circ} \mathrm{C}: 17.9 \mathrm{~cm}^{3}$ & $92.6 \%$ at $45^{\circ} \mathrm{C} ; 86.9 \%$ at $52^{\circ} \mathrm{C}$ \\
\hline Sloan et al., 2013 & $17.1 \pm 13.5 \min ^{*} \ddagger$ & $78 \%(57-90 \%)$ & $43^{\circ} \mathrm{C}$ at periphery for $2-60 \mathrm{~min}$ \\
\hline Mohammadi et al., $2014^{44}$ & median 7.5 hrs (2-16 hrs)† & $\begin{array}{l}\text { high-dose: } 91 \% \text { (28-100\%), } 0.66 \mathrm{~cm}^{3} \text { un- } \\
\text { treated; low-dose: } 98 \% \text { (34-100\%), } 0.19 \\
\mathrm{~cm}^{3} \text { untreated }\end{array}$ & $43^{\circ} \mathrm{C}$ at periphery for $2-10 \mathrm{~min}$ \\
\hline
\end{tabular}

\footnotetext{
* Laser time.

$\uparrow$ Total operative time.

$\ddagger$ Values expressed as the mean \pm SD.
} 
Laser ablation for gliomas

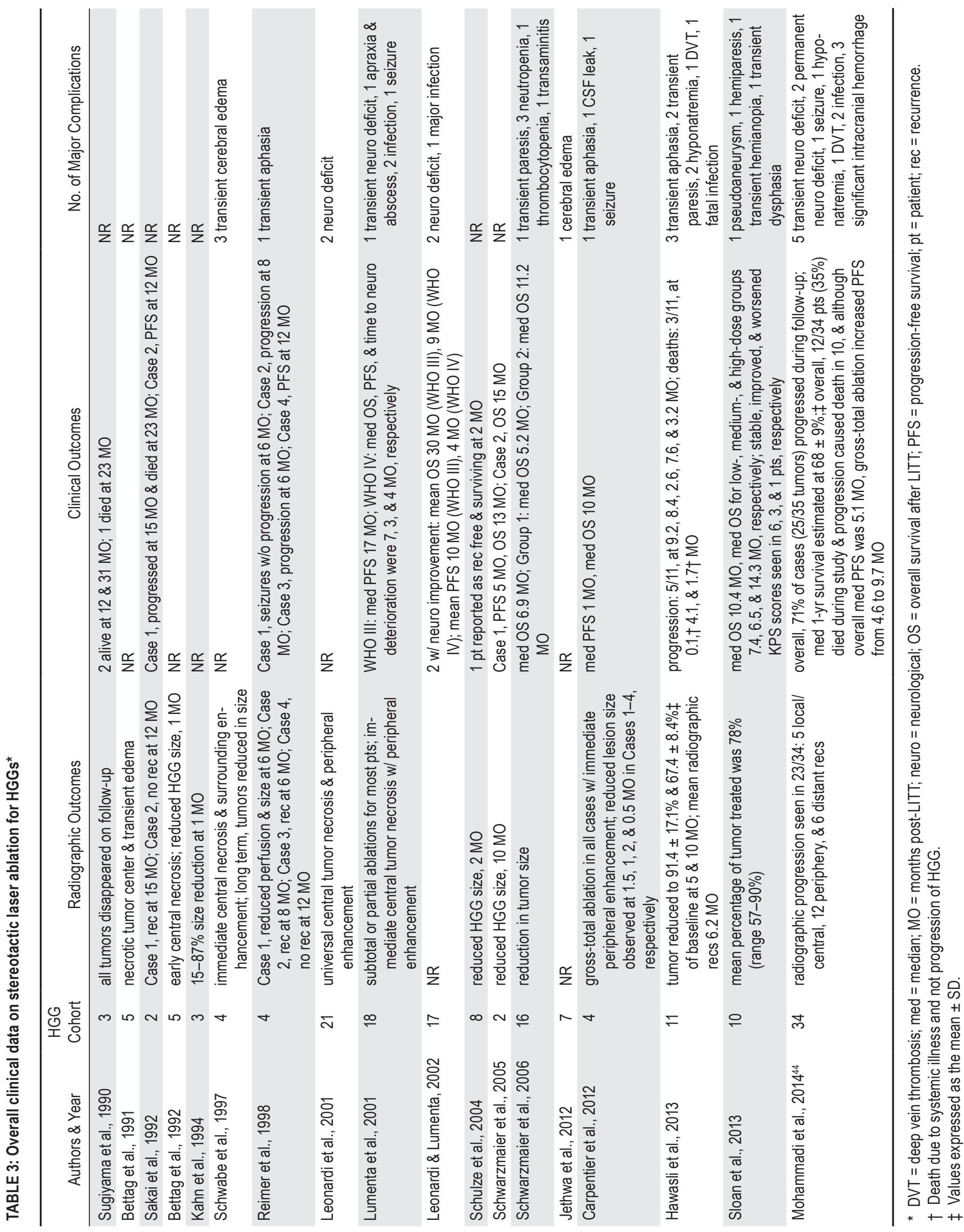


TABLE 4: Stereotactic laser ablation for recurrent HGGs: radiographic volumetric data

\begin{tabular}{|c|c|c|c|c|}
\hline Authors \& Year & Pre-Tx Tumor Size & $\begin{array}{l}\text { Post-Tx Tumor } \\
\text { Size }\end{array}$ & Change in Size & $\begin{array}{c}\text { Time to Radiographic } \\
\text { Response }\end{array}$ \\
\hline Sugiyama et al., 1990 & $1.2-3 \mathrm{~cm}^{*}$ & NR & NR & NR \\
\hline Kahn et al., 1994 & $1.8-2.7 \mathrm{~cm}^{*}$ & $0.5-1.7 \mathrm{~cm}^{*}$ & $11-81 \%$ reduction & $50-100$ days \\
\hline Reimer et al., 1998 & $1-3.5 \mathrm{~cm}^{*}\left(4.2-110 \mathrm{~cm}^{3}\right)$ & NR & NR & $1.5-3 \mathrm{mos}$ \\
\hline Leonardi et al., 2001 & $2.2 \mathrm{~cm}^{*}\left(21.2 \mathrm{~cm}^{3}\right)$ & NR & NR & NR \\
\hline Lumenta et al., 2001 & $2.8 \mathrm{~cm}^{*}\left(21.2 \mathrm{~cm}^{3}\right)$ & 16.3 & $23 \%$ decrease & 7 wks \\
\hline Leonardi \& Lumenta, 2002 & $2.1-2.6 \mathrm{~cm}^{*}\left(\mathrm{III}, 2.1 \mathrm{~cm}^{3} ; \mathrm{IV}, 2.6 \mathrm{~cm}^{3}\right)$ & NR & NR & NR \\
\hline Schulze et al., 2004 & NR & NR & qualitative size reduction reported & 2 wks \\
\hline Schwarzmaier et al., 2005 & $12 \& 2 \mathrm{~cm}^{*}\left(\right.$ mean $\left.20 \mathrm{~cm}^{3}\right)$ & $10 \& 0.5 \mathrm{~cm}^{*}$ & $17 \% \& 75 \%$ reduction & $8 \& 33$ mos \\
\hline Schwarzmaier et al., 2006 & $21.6 \pm 18.6 \mathrm{~cm}^{3} \dagger$ & NR & NR & NR \\
\hline Jethwa et al., 2012 & $9 \mathrm{~cm}^{3}\left(0.37-68.9 \mathrm{~cm}^{3}\right)$ & NR & NR & NR \\
\hline Carpentier et al., 2012 & $2 \mathrm{~cm}^{*}\left(0.38-5.5 \mathrm{~cm}^{*}\right) ; 3.83-8.86 \mathrm{~cm}^{3}$ & $0.1-3 \mathrm{~cm}^{3}$ & $50-90 \%$ reduction & $7-60$ days \\
\hline Hawasli et al., 2013 & $14.1 \pm 10.7 \mathrm{~cm}^{3} \dagger$ & $9.5 \mathrm{~cm}^{3}$ & $33 \%$ reduction & $7-10$ mos \\
\hline Sloan et al., 2013 & $6.8 \mathrm{~cm}^{*}\left(2.6-19 \mathrm{~cm}^{*}\right) ; 2.6-19 \mathrm{~cm}^{3}$ & NR & NR & $24-48 \mathrm{hrs}$ \\
\hline Mohammadi et al., $2014^{44}$ & $0.7-49.9 \mathrm{~cm}^{3}$ & NR & NR & NR \\
\hline
\end{tabular}

or mean progression-free survival ranged from 1 to 17 months post-LITT. The median or mean overall survival post-LITT ranged from 6.9 to 30 months. ${ }^{13,27,38,41,44,64,65,67}$ Most recently, Mohammadi et al. reported a 1-year estimated survival after LITT for mixed recurrent and newly diagnosed HGGs at $68 \%$ and overall progression-free survival at 5.1 months post-LITT. ${ }^{44}$ Several authors have noted similar factors that contribute to better response to LITT. Consistent with traditional surgery, Mohammadi et al. found that a greater extent of ablation (i.e., grosstotal ablation) increased progression-free survival from 4.6 to 9.7 months post-LITT. ${ }^{44}$ In addition to greater extent of ablation, higher-dose LITT may also be associated with improved radiographic responses and clinical outcomes. ${ }^{27,41,67}$

Eleven studies reported a total of 52 complications, some more severe than others. For the most common complications in the overall cohort of 174 patients, there were 4 reports of cerebral edema (2\%), which typically improved with time and steroid therapy; 30 reports (17\%) of neurological deficits or injury (many transient); and 6 (3\%) reports of infection. Karnofsky Performance Scale (KPS) data were reported in 9 studies (Table 5). Preoperative KPS scores ranged from 0 to 100 and, when reported, postoperative KPS scores ranged from 40 to 90.

The varying reporting measures, mixed patient cohorts, mix of newly diagnosed and recurrent tumors, often lower performance statuses, difficult tumor locations, and duplication undoubtedly make interpretation of these data difficult. These limitations are magnified by adjuvant therapies and their potential effects on outcomes and by varying times of total follow-up (Table 5). Nonetheless, outcome results from these heterogeneous studies with mixed recurrent and newly diagnosed WHO Grade IV HGGs highlight LITT as a potential treatment option for HGGs. Furthermore, when taken as a whole, the cumulative data suggest that gross-total LITT may provide some benefit for patients with HGG who do not qualify for traditional surgical options. Therefore, the current combined data show suggestions of clinical benefit and provide equipoise for better-controlled clinical investigations.

\section{Stereotactic Laser Ablation for WHO Grade III Versus Grade IV HGGs}

The LITT data for HGGs often included both Grades III and IV tumors as mixed cohorts. One-third of the tumors treated were Grade III. Given the differences in pathology and outcomes between grades, this mixture makes interpretation of data somewhat difficult. Fortunately, several authors have reported separate outcome measures for the 2 grades or have only included WHO Grade IV tumors in their case series. Lumenta et al. and Leonardi and Lumenta reported that median progressionfree survival for WHO III HGGs was 17 and 10 months post-LITT, respectively. ${ }^{38,41}$ Leonardi and Lumenta found that overall survival for WHO Grade III tumors was 20 months post-LITT. ${ }^{38}$ Several authors reported WHO Grade IV-specific outcome data. ${ }^{13,38,41,64,65,67}$ Progressionfree survival for WHO Grade IV HGGs ranged from 1 to 5 months post-LITT. Overall survival post-LITT ranged from 7 to 15 months.

\section{Stereotactic Laser Ablation as a Salvage Therapy for Recurrent HGG: Subgroup Review}

Repeat resection plus chemotherapy increases survival for patients with recurrent HGGs from 6 months to 9 months when compared with chemotherapy alone. ${ }^{5}$ Unfortunately, not all patients are candidates for open surgery. For these individuals, several groups have enrolled patients in clinical trials to evaluate whether adding minimally invasive LITT could improve outcomes when compared with chemotherapy alone. Twelve articles reported 
Laser ablation for gliomas

TABLE 5: Stereotactic laser ablation for recurrent HGGs: performance and adjuvants*

\begin{tabular}{|c|c|c|c|c|}
\hline Authors \& Year & $\begin{array}{l}\text { Pre-LITT KPS } \\
\text { (range) }\end{array}$ & Post-LITT KPS & $\begin{array}{l}\text { Follow-Up Time From } \\
\text { LITT (range) }\end{array}$ & Adjuvant Tx w/ LITT (no. of pts) \\
\hline Sugiyama et al., 1990 & $100,0, \& 80$ & NR & $31,23, \& 9 \mathrm{MO}$ & NR \\
\hline Sakai et al., 1992 & $0 \& 90$ & NR & $23 \& 12 \mathrm{MO}$ & all received $\mathrm{ACNU}$ \\
\hline Kahn et al., 1994 & NR & NR & $13,9, \& 6 \mathrm{MO}$ & 1 received XRT \\
\hline Lumenta et al., 2001 & NR & NR & $3.5-4.2 \mathrm{MO}$ & NR \\
\hline Leonardi \& Lumenta, 2002 & $\begin{array}{l}\text { III: mean } 78 ; \text { IV: } \\
\quad \text { mean } 69\end{array}$ & $\begin{array}{l}\text { III: } 50 \% \text { deteriorated, } 50 \% \\
\text { unchanged; IV: } 100 \% \text { deterio- } \\
\text { rated after } 1-3 \mathrm{MO}\end{array}$ & NR & NR \\
\hline Schwarzmaier et al., 2005 & $60 \& 70$ & $70 \& 50$ & $30 \& 15 \mathrm{MO}$ & TMZ \\
\hline Schwarzmaier et al., 2006 & 70 & NR & $9.1 \pm 6.3 \mathrm{MO}$ & $\begin{array}{l}\text { TMZ, DOX; DOX + ACNU; ACNU + } \\
\text { TEN; THAL }\end{array}$ \\
\hline Carpentier et al., 2012 & $70,50,90, \& 90$ & NR & through death & $\begin{array}{l}\text { Cases 1, 2, \& 4: IR \& BEV after rec; } \\
\text { Case 3: BCNU \& TMZ }\end{array}$ \\
\hline Hawasli et al., 2013 & 74.1 & $40-90$ & $5.8 \mathrm{MO}(0.1-11.2 \mathrm{MO})$ & $\begin{array}{l}\text { newly diagnosed: TMZ/XRT; salvage: } \\
\text { BEV (3) }\end{array}$ \\
\hline Sloan et al., 2013 & $80(70-90)$ & $\begin{array}{l}\text { low-dose LITT: no change; high- } \\
\text { dose LITT: } 10 \text { - to } 20 \text {-point } \\
\text { improvement at } 2 \text { wks }\end{array}$ & $15 \mathrm{MO}(3.6-39 \mathrm{MO})$ & NR \\
\hline Mohammadi et al., $2014^{44}$ & $80(50-90)$ & NR & $7.2 \mathrm{MO}$ & $\begin{array}{l}\text { newly diagnosed: TMZ/XRT; salvage: } \\
\text { TMZ (6), Cytoxan (3), BEV (2), } \\
\text { CCNU (2), PCB (1) }\end{array}$ \\
\hline
\end{tabular}

\footnotetext{
* $\mathrm{ACNU}=$ nimustine; $\mathrm{BEV}=$ bevacizumab; $\mathrm{CCNU}=$ lomustine; $\mathrm{DOX}=$ liposomal doxorubicin; $\mathrm{IR}$ = irinotecan; $\mathrm{PCB}=$ procarbazine; $\mathrm{TEN}=$ teniposide;
} $\mathrm{THAL}=$ thalidomide; $\mathrm{TMZ}=$ temozolomide; $\mathrm{XRT}=$ radiotherapy.

the use of LITT for 106 patients with recurrent HGGs (Table 6). Eight articles reported outcomes for salvagespecific HGG treatments and 4 did not. In 6 articles, only patients with recurrent HGGs were reported. Among the largest cohorts, Leonardi and Lumenta reported results on recurrent HGGs and stratified by tumor grade. Leonardi and Lumenta report that the mean progressionfree survival for recurrent Grade III and IV HGGs was 10 and 4 months, respectively. ${ }^{38}$ The mean overall survival for recurrent Grade III and IV HGGs was 30 and 9 months, respectively. ${ }^{38}$ Schwarzmaier et al. reported that the overall survival of 16 patients with recurrent $\mathrm{HGG}$ after LITT was 11.2 months ${ }^{65}$ Carpentier et al. reported that overall survival among 4 patients with HGGs was 10 months after LITT. ${ }^{13}$ Most recently, Sloan et al. reported that survival in patients treated with salvage high-dose LITT was 15.2 months. ${ }^{67}$ Hence, subgroup analysis of recurrent HGGs found that treatment with LITT may lead to an overall survival of 9-15.2 months after treatment. Although adjuvant therapies are probably contributing to this promising outcome, it appears to be similar to previously published survival rates seen with traditional open surgery and chemotherapy. These data suggest that LITT may serve as a viable salvage treatment.

De Novo Stereotactic Laser Ablation for Newly Diagnosed HGGs: Subgroup Review

Retrospective data suggest that GTR of newly diagnosed HGGs increases median survival from 8 to 13 months. ${ }^{12}$ This has been corroborated by prospective Level II evidence that greater extent of resection of HGGs improves both quality of life and length of survival. ${ }^{11} \mathrm{Un}$ fortunately, not all patients with HGGs are candidates for a craniotomy for tumor resection. In 5 studies, authors reported treating a total of 40 patients with newly diagnosed HGGs (de novo therapy; i.e., first-time therapy). Although it was not consistently reported, most were treated with LITT rather than open traditional resection due to tumor location or patient factors preventing open resection. Reporting of de novo-specific therapy outcomes is even more sparse and difficult to interpret than for recurrent lesions. Sakai et al. treated a parietal newly diagnosed de novo tumor and reported no evidence of progression or recurrence at 12 months post-LITT (Table 3) ${ }^{60}$ Hawasli et al. reported recurrence at 2.6 and 3.2 months in 2 of 7 patients with de novo lesions, but had a short study window for 3 of 7 patients. ${ }^{27}$ One of 7 patients died at 4.1 months due to tumor progression. Despite the data available for all HGGs, outcome data on de novo-treated HGGs is very sparse. Therefore, without additional clinical experience, it is difficult to draw any specific conclusions about this subset of patients.

\section{Discussion}

\section{Controversy Over Focal Therapy for HGGs}

It is well established that HGG tumor cells often metastasize great distances from the enhancing portion of the tumor and sometimes even to the contralateral hemisphere. ${ }^{52,77}$ Despite retrospective studies supporting the use of stereotactic radiosurgery for HGGs, randomized 
TABLE 6: Stereotactic laser ablation for recurrent HGGs: subgroup analysis

\begin{tabular}{|c|c|c|}
\hline Authors \& Year & $\begin{array}{l}\text { Recurrent } \\
\text { HGG Cohort }\end{array}$ & Outcomes After LITT for Recurrent HGGs \\
\hline Sakai et al., 1992 & 1 & rec at $15 \mathrm{MO}$, death at $23 \mathrm{MO}$ \\
\hline Reimer et al., 1998 & 4 & $\begin{array}{l}\text { Case } 1 \text {-reduced perfusion \& size at } 6 \mathrm{MO} \text {; Case } 2 \text {-rec at } 8 \mathrm{MO} \text {; Case } 3 \text {-rec at } 6 \mathrm{MO} \text {; Case } 4 \text {-no rec } \\
\text { at } 12 \mathrm{MO}\end{array}$ \\
\hline Leonardi et al., 2001 & 21 & $\begin{array}{l}\text { initial radiographic central tumor necrosis \& peripheral enhancement; clinical outcomes for salvage- } \\
\text { specific therapy NR }\end{array}$ \\
\hline Lumenta et al., 2001 & 5 & $\begin{array}{l}\text { initial radiographic central tumor necrosis \& peripheral enhancement; clinical outcomes for salvage- } \\
\text { specific therapy NR }\end{array}$ \\
\hline Leonardi \& Lumenta, 2002 & $17^{*}$ & $\begin{array}{l}2 \text { w/ neuro improvement; mean OS for WHO III \& IV was } 30 \text { \& } 9 \text { MO, respectively; mean PFS for WHO III \& IV } \\
\text { was } 10 \text { \& } 4 \text { MO, respectively; KPS was maintained above } 70 \text { for } 15 \mathrm{MO} \text { (WHO III) \& } 7.5 \mathrm{MO} \text { (WHO IV) }\end{array}$ \\
\hline Schwarzmaier et al., 2005 & 2 & Case 1: reduced tumor vol at $10 \mathrm{MO}$, OS $13 \mathrm{MO}$; Case 2: reduced tumor vol at $10 \mathrm{MO}$, OS $15 \mathrm{MO}$ \\
\hline Schwarzmaier et al., 2006 & 16 & reduced tumor size; overall med OS 6.9 MO; med OS (early group) 5.2 MO; med OS (late group) $11.2 \mathrm{MO}$ \\
\hline Jethwa et al., 2012 & 4 & NR \\
\hline Carpentier et al., 2012 & 4 & $\begin{array}{l}\text { gross-total ablation in all cases w/ immediate peripheral enhancement; reduced tumor size observed in all } \\
\text { pts }(0.5-1.5 \mathrm{MO}) \text {; med PFS \& OS were } 1 \& 10 \mathrm{MO} \text {, respectively }\end{array}$ \\
\hline Hawasli et al., 2013 & 4 & $\begin{array}{l}\text { radiographic tumor vol decreased (Case } 1 \text { ) or was stable (Cases 2-4) on follow-up imaging; } 3 \text { of } 4 \text { tumors } \\
\text { recurred at } 9.2,8.4, \& 7.6 \text { mos, \& } 0 \text { pts died during the study }\end{array}$ \\
\hline Sloan et al., 2013 & 10 & $\begin{array}{l}78 \% \text { of tumor vol treated; low-dose OS } 314,265, \& 96 \text { days; medium-dose OS } 334 \& 62 \text { days; } \& \text { high-dose } \\
\text { OS } 485,305,319,434, \& 767 \text { days }\end{array}$ \\
\hline Mohammadi et al., $2014^{44}$ & $19 \dagger$ & outcomes after salvage-specific therapy NR \\
\hline
\end{tabular}

* Reported as "nearly all" recurrent HGGs.

$\dagger 19$ tumors in 18 patients.

prospective studies found no survival benefit for radiosurgery when added to conventional radiation. ${ }^{69}$ This observation could be used to argue against a significant effect on outcome for a focal therapy such as LITT. However, modern radiosurgery does not produce an effect on tissue for several weeks to months, ${ }^{48}$ LITT should more appropriately be compared with open resection, which is acutely cytoreductive and has been shown to have an impact on HGGs. ${ }^{1,5,11,12}$ The LITT procedure can produce an acute gross-total ablation that immediately coagulates the entire enhancing portion of the tissue or induce short-term necrosis and apoptosis. ${ }^{47,59,60,62}$ This has been observed radiographically as immediate central necrosis of the tumor. Furthermore, beyond the analogy of resection, preliminary animal studies in LITT have indeed shown that laser ablation acutely leads to breakdown of the BBB. ${ }^{3,4,6,7,73}$ The breakdown in the $\mathrm{BBB}$ in regions where metastatic cells may reside may potentiate adjuvant therapy and immune reactions postulated to occur after LITT. These properties of LITT have the potential to exert positive effects to a wider area than the ablated region. Furthermore, with advanced intraoperative imaging capabilities, LITT has the potential to achieve grosstotal ablation without the morbidity of open surgery. These findings argue that LITT offers acute ablation of the tumor and should not necessarily be compared with historical results in radiosurgery trials.

Use of LITT for Select Patients With HGG: Incorporating a Laser Therapy Into a Standard Practice Algorithm

After GTR and temozolomide plus radiation com- bination therapy, standard management algorithms for newly diagnosed HGGs may vary slightly from institution to institution depending on clinical trials. Treatment strategies for recurrent HGGs are probably even more disparate from hospital to hospital. Clinical trials vary from immunotherapies to targeted molecular therapies, and many require a significant amount of tumor sample for vaccine generation or correlative studies. However, for some patients open surgery is not an option due to deep location of the tumor or comorbid conditions. Review of the literature revealed that approximately $20 \%$ of HGGs with LITT treated thus far have been in deep locations, especially the thalamus and basal ganglia. For this group of patients, LITT offered a minimally invasive option with reduced operative times, less blood loss, and shorter hospital stays. ${ }^{27,67}$ Generally, LITT may serve as a cytoreductive option for some of these patients over biopsy alone or no surgery at all.

Because the data on LITT for HGGs consist of Level IV evidence, additional clinical experience is essential to evaluate the efficacy of LITT in both newly diagnosed and recurrent HGGs. To achieve additional experience and data, it would be beneficial to incorporate LITT into the treatment algorithms of patients with HGG (Fig. 4). If a patient with newly diagnosed HGG is a viable surgical candidate and is interested in traditional resection, we propose that they continue with standard of care traditional craniotomy for gross-total and maximally safe resection and tissue collection, followed by standard chemoradiation in or outside of a clinical trial (Fig. 4A, left column). However, if a patient presents with newly diagnosed HGG and is not a candidate for open resection (e.g., due to difficult to access 


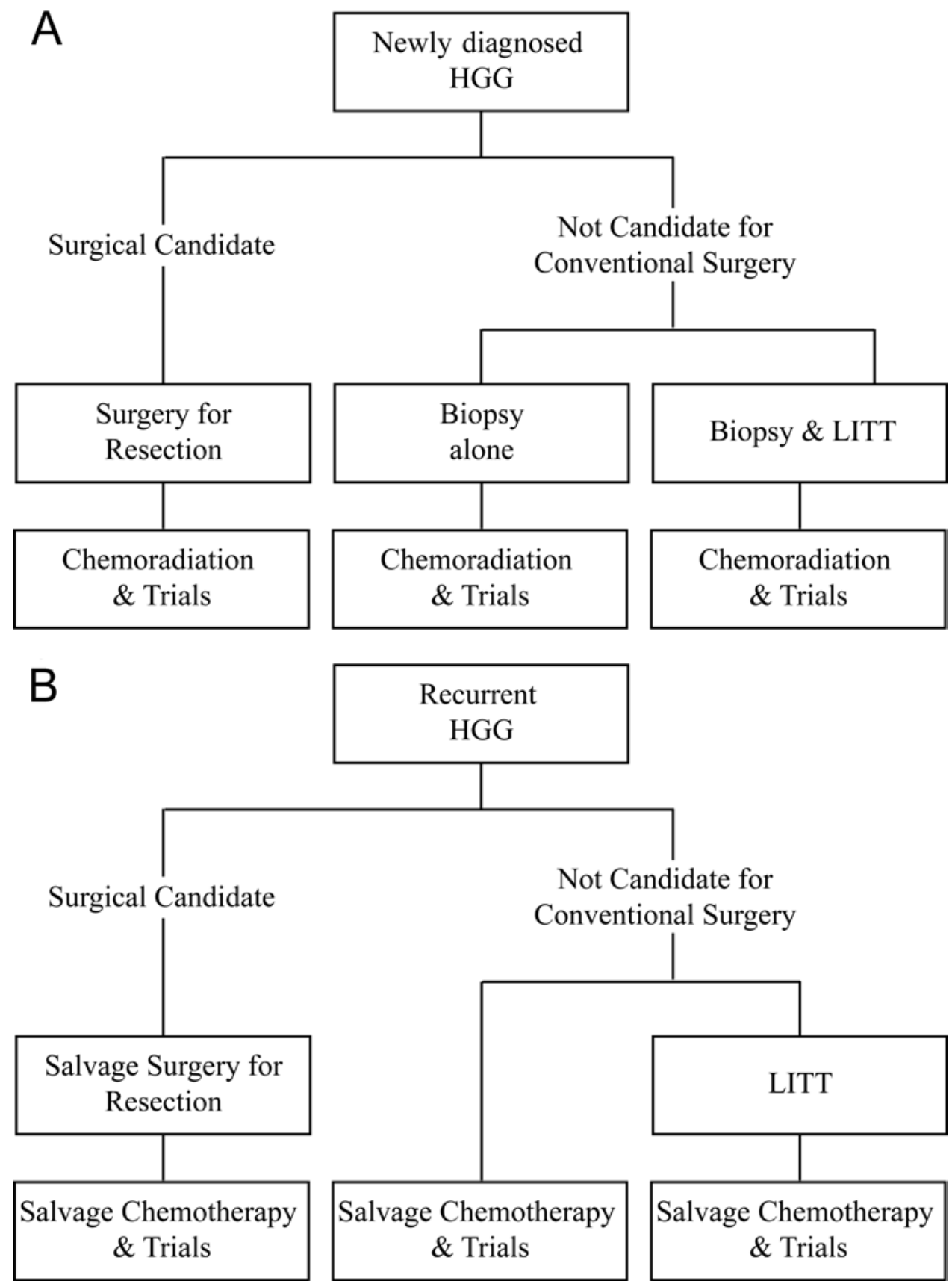

FIG. 4. Management algorithm for patients with HGG that includes LITT for the treatment of (A) newly diagnosed and (B) recurrent HGGs.

tumor in the thalamus) or declines traditional surgery, 2 surgical options can be offered: 1) standard of care biopsy alone (Fig. 4A, center column); or 2) needle biopsy and treatment with stereotactic LITT (Fig. 4A, right column). An open biopsy may be performed with craniotomy for the collection of adequate tumor volume needed for some immunotherapy and clinical trials: that is a clear advantage of this option (Fig. 4A, center column). For patients undergoing stereotactic needle biopsy (Fig. 4A, right column), the biopsy procedure could be immediately followed by grosstotal LITT of the tumor. All treatments would be followed by chemoradiation.
The typical pathways available for recurrent tumors are more limited due to of the lack of effective conventional therapies. Level II-III evidence supports repeat resection follow by salvage chemotherapy and clinical trial participation (Fig. 4B, left column). However, patients who are not candidates or who decline traditional resection can either immediately begin salvage chemotherapy within or outside of clinical trials (Fig. 4B, center column), or they may be offered salvage LITT followed by salvage chemotherapy (Fig. 4B, right column). Creating a streamlined and clinically reasonable management algorithm to enroll candidates for LITT will generate the 
data necessary to evaluate treatment efficacy with casecontrol cohorts.

\section{Emerging Application-Laser Therapy as a Potential Adjunct to Chemotherapy}

Enhanced Delivery of Chemotherapy. To circumvent the $\mathrm{BBB}$ in local drug delivery to the brain, recent approaches have focused on bypassing it. One method is the use of Gliadel wafers, a polymer implant impregnated with BCNU, which are placed intraoperatively in the resection cavity to circumvent the $\mathrm{BBB}$. This approach resulted in a statistically significant but modest improvement in survival in both newly diagnosed and recurrent GBM. ${ }^{10,78,79}$ The modest survival benefit of Gliadel could be due to the short duration of drug delivery, because most BCNU is released within 5 days. ${ }^{20}$ However, the fact that 5 days of direct BCNU delivery can improve survival of patients with GBM to a degree approaching that achieved by 8 months of systemic chemotherapy is remarkable in itself, supporting the hypothesis that the $\mathrm{BBB}$ is a critical barrier to the cytotoxic chemotherapy effect. Unfortunately, Gliadel is not widely used due to its complication profile. Another approach to bypassing the $\mathrm{BBB}$ is the convection-enhanced delivery system, in which a catheter is surgically inserted into the tumor to deliver chemotherapy. ${ }^{8}$ This invasive procedure requires prolonged hospitalization and meticulous maintenance of the external catheter to prevent serious complications, and as a result remains investigational and is rarely used.

Disruption of Peritumoral BBB. The use of MRIguided LITT to induce sustained disruption of the peritumoral BBB raises the intriguing possibility that laser ablation might not simply represent a tool for cytoreduction, but might also be a vehicle for enhancing drug delivery. During LITT, the maximal temperature in the core can reach greater than $70^{\circ} \mathrm{C}$, resulting in coagulation necrosis. The temperature in the peritumoral region is lower but remains high enough $\left(>40^{\circ} \mathrm{C}\right)$ to disrupt the $\mathrm{BBB}$. This has been histologically demonstrated by local extravasation of dyes, antibodies, and chemotherapy. ${ }^{47,59,60,62}$ Disruption of the BBB is radiographically evidenced by new peritumoral contrast enhancement extending several centimeters from the tumor edge (versus the original tumor enhancement that is lost due to the heat ablation). These observations suggest that an interesting byproduct of laser ablation is the disruption of the peritumoral $\mathrm{BBB}$. These radiographic changes often persist for several weeks, providing a rare window of opportunity during which drug delivery can potentially be enhanced to eliminate infiltrative tumor cells in the tumor periphery, where most recurrences occur.

Although the procedure remains under investigation, current data show that LITT causes BBB disruption. ${ }^{22,47,54,59,60,62}$ Indeed, the role of hyperthermia in increasing $\mathrm{BBB}$ permeability has been previously described in several animal models of brain hyperthermia. In a rodent model of human glioma, the global heating of a mouse's head to $42^{\circ} \mathrm{C}$ for 30 minutes in a warm water bath significantly increased the maximal brain concentration of a thermosensitive liposome encapsulated with the chemotherapeutic drug Adriamycin. ${ }^{22}$ To affect locoregional hyperthermia in the brain, retrograde infusion of a hyperthermic saline solution at $43^{\circ} \mathrm{C}$ into the rat left external carotid artery reversibly increased BBB permeability to Evans blue albumin in the left cerebral hemisphere. ${ }^{54}$ In the most analogous method to LITT in humans, LITT in rodents resulted in locoregional disruption of the BBB as evidenced by increased locoregional passage of the Evans blue dye, serum proteins (e.g., fibrinogen and $\operatorname{IgM}$ ), and the cytotoxic drug paclitaxel. ${ }^{59}$ Based on these data, it is reasonable to hypothesize that hyperthermia-induced disruption of the peritumoral BBB by LITT represents a potential tool to enhance delivery of chemotherapy to this region and effectively target residual disease, in addition to primary cytoreduction. Indeed, clinical trials are underway to test this in patients with recurrent HGGs (http://clinicaltrials.gov/show/NCT01851733).

\section{Conclusions}

The clinical data and guidelines support traditional GTR as the standard of care for both newly diagnosed and, occasionally, for recurrent tumors. However, data presented in this review suggest that LITT may serve as a viable focal treatment option for HGG in patients who are not candidates for open resection. The literature currently available is Level IV evidence without case-matched controls. Therefore, although results are promising, conclusions remain limited. The mixed results for LITT for HGGs are probably due to many factors including mixed patient cohorts, a lack of control data, treatment factors, tumor grades, concurrent therapies, and a combination of recurrence and newly diagnosed tumors. When evaluated as a subgroup, recurrent tumors appeared to have a median survival time potentially better than historical controls, but case-controlled data are currently unavailable. To date, subgroup analysis of de novo treatment for newly diagnosed tumors is less conclusive. Going forward, LITT may be incorporated into a rigorous patient treatment algorithm used by multidisciplinary neuro-oncology groups to better refine and understand clinical efficacy and indications.

\section{Acknowledgment}

We acknowledge support from the Department of Neurosurgery, Washington University School of Medicine.

\section{Disclosure}

Dr. Leuthardt has a consulting relationship with Monteris Medical. Dr. Hawasli received funding from the NIH (Grant No. 5T32NS007205-32).

Author contributions to the study and manuscript preparation include the following. Conception and design: Leuthardt, Hawasli. Acquisition of data: Hawasli, Kim, Dunn, Tran. Analysis and interpretation of data: all authors. Drafting the article: all authors. Critically revising the article: all authors. Reviewed submitted version of manuscript: Leuthardt, Hawasli. Approved the final version of the manuscript on behalf of all authors: Leuthardt. Statistical analysis: Dunn. Administrative/technical/material support: Leuthardt, Hawasli, Kim. Study supervision: Leuthardt, Kim, Dunn, Tran. 


\section{References}

1. Ammirati M, Galicich JH, Arbit E, Liao Y: Reoperation in the treatment of recurrent intracranial malignant gliomas. Neurosurgery 21:607-614, 1987

2. Anzai Y, Lufkin R, DeSalles A, Hamilton DR, Farahani K, Black KL: Preliminary experience with MR-guided thermal ablation of brain tumors. AJNR Am J Neuroradiol 16:39_ 52, 1995

3. Ascher PW, Justich E, Schröttner O: Interstitial thermotherapy of central brain tumors with the Nd:YAG laser under real-time monitoring by MRI. J Clin Laser Med Surg 9:79-83, 1991

4. Ascher PW, Justich E, Schröttner O: A new surgical but less invasive treatment of central brain tumours. Preliminary report. Acta Neurochir Suppl (Wien) 52:78-80, 1991

5. Barker FG II, Chang SM, Gutin PH, Malec MK, McDermott MW, Prados MD, et al: Survival and functional status after resection of recurrent glioblastoma multiforme. Neurosurgery 42:709-723, 1998

6. Bettag M, Ulrich F, Schober R, Fürst G, Langen KJ, Sabel M, et al: Stereotactic laser therapy in cerebral gliomas. Acta Neurochir Suppl (Wien) 52:81-83, 1991

7. Bettag M, Ulrich F, Schober R, Hessel S, Sabel M: Experimental and first clinical results of Nd:YAG laser-induced hyperthermia in brain tumours, in Waidelich W, Waidelich R, Hofstetter A (eds): Laser in Medicine. Berlin: Springer-Verlag, 1992, pp 210-213

8. Bobo RH, Laske DW, Akbasak A, Morrison PF, Dedrick RL, Oldfield EH: Convection-enhanced delivery of macromolecules in the brain. Proc Natl Acad Sci U S A 91:2076-2080, 1994

9. Brandes AA, Tosoni A, Cavallo G, Bertorelle R, Gioia V, Franceschi E, et al: Temozolomide 3 weeks on and 1 week off as first-line therapy for recurrent glioblastoma: phase II study from gruppo italiano cooperativo di neuro-oncologia (GICNO). Br J Cancer 95:1155-1160, 2006

10. Brem H, Piantadosi S, Burger PC, Walker M, Selker R, Vick NA, et al: Placebo-controlled trial of safety and efficacy of intraoperative controlled delivery by biodegradable polymers of chemotherapy for recurrent gliomas. Lancet 345:1008-1012, 1995

11. Brown PD, Maurer MJ, Rummans TA, Pollock BE, Ballman $\mathrm{KV}$, Sloan JA, et al: A prospective study of quality of life in adults with newly diagnosed high-grade gliomas: the impact of the extent of resection on quality of life and survival. Neurosurgery 57:495-504, 2005

12. Bucci MK, Maity A, Janss AJ, Belasco JB, Fisher MJ, Tochner ZA, et al: Near complete surgical resection predicts a favorable outcome in pediatric patients with nonbrainstem, malignant gliomas: results from a single center in the magnetic resonance imaging era. Cancer 101:817-824, 2004

13. Carpentier A, Chauvet D, Reina V, Beccaria K, Leclerq D, McNichols RJ, et al: MR-guided laser-induced thermal therapy (LITT) for recurrent glioblastomas. Lasers Surg Med 44:361368,2012

14. Central Brain Tumor Registry of the United States: 2013 Fact Sheet. (http://www.cbtrus.org/factsheet/factsheet.html) [Accessed October 15, 2014]

15. Chicoine MR, Lim CC, Evans JA, Singla A, Zipfel GJ, Rich $\mathrm{KM}$, et al: Implementation and preliminary clinical experience with the use of ceiling mounted mobile high field intraoperative magnetic resonance imaging between two operating rooms. Acta Neurochir Suppl 109:97-102, 2011

16. Dirks P, Bernstein M, Muller PJ, Tucker WS: The value of reoperation for recurrent glioblastoma. Can J Surg 36:271-275, 1993

17. Fazeny-Dörner B, Wenzel C, Veitl M, Piribauer M, Rössler K, Dieckmann K, et al: Survival and prognostic factors of patients with unresectable glioblastoma multiforme. Anticancer Drugs 14:305-312, 2003
18. Fisher JL, Schwartzbaum JA, Wrensch M, Wiemels JL: Epidemiology of brain tumors. Neurol Clin 25:867-890, vii, 2007

19. Flanders VL, Gervais DA: Ablation of liver metastases: current status. J Vasc Interv Radiol 21 (8 Suppl):S214-S222, 2010

20. Fleming AB, Saltzman WM: Pharmacokinetics of the carmustine implant. Clin Pharmacokinet 41:403-419, 2002

21. Friedman HS, Prados MD, Wen PY, Mikkelsen T, Schiff D, Abrey LE, et al: Bevacizumab alone and in combination with irinotecan in recurrent glioblastoma. J Clin Oncol 27:47334740, 2009

22. Gong W, Wang Z, Liu N, Lin W, Wang X, Xu D, et al: Improving efficiency of adriamycin crossing blood brain barrier by combination of thermosensitive liposomes and hyperthermia. Biol Pharm Bull 34:1058-1064, 2011

23. Gonzalez-Martinez J, Vadera S, Mullin J, Enatsu R, Alexopoulos AV, Patwardhan R, et al: Robot-assisted stereotactic laser ablation in medically intractable epilepsy: operative technique. Neurosurgery 10 Suppl 2:167-173, 2014

24. Grossman SA, Ye X, Piantadosi S, Desideri S, Nabors LB, Rosenfeld M, et al: Survival of patients with newly diagnosed glioblastoma treated with radiation and temozolomide in research studies in the United States. Clin Cancer Res 16:24432449,2010

25. Gulati S, Jakola AS, Nerland US, Weber C, Solheim O: The risk of getting worse: surgically acquired deficits, perioperative complications, and functional outcomes after primary resection of glioblastoma. World Neurosurg 76:572-579, 2011

26. Harsh GR IV, Levin VA, Gutin PH, Seager M, Silver P, Wilson CB: Reoperation for recurrent glioblastoma and anaplastic astrocytoma. Neurosurgery 21:615-621, 1987

27. Hawasli AH, Bagade S, Shimony JS, Miller-Thomas M, Leuthardt EC: Magnetic resonance imaging-guided focused laser interstitial thermal therapy for intracranial lesions: single-institution series. Neurosurgery 73:1007-1017, 2013

28. Hawasli AH, Ray WZ, Murphy RK, Dacey RG Jr, Leuthardt EC: Magnetic resonance imaging-guided focused laser interstitial thermal therapy for subinsular metastatic adenocarcinoma: technical case report. Neurosurgery 70 (2 Suppl Operative):332-338, 2012

29. Hirschberg H, Samset E, Hol PK, Tillung T, Lote K: Impact of intraoperative MRI on the surgical results for high-grade gliomas. Minim Invasive Neurosurg 48:77-84, 2005

30. Hong B, Wiese B, Bremer M, Heissler HE, Heidenreich F, Krauss JK, et al: Multiple microsurgical resections for repeated recurrence of glioblastoma multiforme. Am J Clin Oncol 36:261-268, 2013

31. Jethwa PR, Barrese JC, Gowda A, Shetty A, Danish SF: Magnetic resonance thermometry-guided laser-induced thermal therapy for intracranial neoplasms: initial experience. Neurosurgery 71 (1 Suppl Operative):133-145, 2012

32. Kahn T, Bettag M, Ulrich F, Schwarzmaier HJ, Schober R, Fürst $\mathrm{G}$, et al: MRI-guided laser-induced interstitial thermotherapy of cerebral neoplasms. J Comput Assist Tomogr 18:519-532, 1994

33. Kahn T, Harth T, Bettag M, Schwabe B, Ulrich F, Schwarzmaier HJ, et al: Preliminary experience with the application of gadolinium-DTPA before MR imaging-guided laser-induced interstitial thermotherapy of brain tumors. J Magn Reson Imaging 7:226-229, 1997

34. Kahn T, Harth T, Kiwit JC, Schwarzmaier HJ, Wald C, Mödder U: In vivo MRI thermometry using a phase-sensitive sequence: preliminary experience during MRI-guided laserinduced interstitial thermotherapy of brain tumors. J Magn Reson Imaging 8:160-164, 1998

35. Karam JA, Ahrar K, Matin SF: Ablation of kidney tumors. Surg Oncol Clin N Am 20:341-353, viii, 2011

36. Kubben PL, ter Meulen KJ, Schijns OE, ter Laak-Poort MP, van Overbeeke JJ, van Santbrink H: Intraoperative MRI-guided resection of glioblastoma multiforme: a systematic review. Lancet Oncol 12:1062-1070, 2011 
37. Lacroix M, Abi-Said D, Fourney DR, Gokaslan ZL, Shi W, DeMonte F, et al: A multivariate analysis of 416 patients with glioblastoma multiforme: prognosis, extent of resection, and survival. J Neurosurg 95:190-198, 2001

38. Leonardi MA, Lumenta CB: Stereotactic guided laser-induced interstitial thermotherapy (SLITT) in gliomas with intraoperative morphologic monitoring in an open MR: clinical expierence. Minim Invasive Neurosurg 45:201-207, 2002

39. Leonardi MA, Lumenta CB, Gumprecht HK, von Einsiedel GH, Wilhelm T: Stereotactic guided laser-induced interstitial thermotherapy (SLITT) in gliomas with intraoperative morphologic monitoring in an open MR-unit. Minim Invasive Neurosurg 44:37-42, 2001

40. Lian H, Guo H, Gan W, Li X, Yan X, Wang W, et al: Cryosurgery as primary treatment for localized prostate cancer. Int Urol Nephrol 43:1089-1094, 2011

41. Lumenta CB, Leonardi MA, von Einsiedel H: Stereotactic guided laser-induced interstitial thermotherapy (SLITT) in gliomas with intraoperative morphologic monitoring in open MR. January 31, 2001. SPIE. (Abstract) (http://proceedings. spiedigitallibrary.org/proceeding. aspx?articleid=922481) [Accessed October 12, 2014]

42. McGirt MJ, Chaichana KL, Gathinji M, Attenello FJ, Than K, Olivi A, et al: Independent association of extent of resection with survival in patients with malignant brain astrocytoma. Clinical article. J Neurosurg 110:156-162, 2009

43. McGirt MJ, Mukherjee D, Chaichana KL, Than KD, Weingart JD, Quinones-Hinojosa A: Association of surgically acquired motor and language deficits on overall survival after resection of glioblastoma multiforme. Neurosurgery 65:463-470, 2009

44. Mohammadi AM, Hawasli AH, Rodriguez A, Schroeder JL, Laxton AW, Elson P, et al: The role of laser interstitial thermal therapy in enhancing progression-free survival of difficult-toaccess high-grade gliomas: a multicenter study. Cancer Med 3:971-979, 2014

45. Mohammadi AM, Schroeder JL: Laser interstitial thermal therapy in treatment of brain tumors-the NeuroBlate System. Expert Rev Med Devices 11:109-119, 2014

46. Nabavi A, Thurm H, Zountsas B, Pietsch T, Lanfermann H, Pichlmeier U, et al: Five-aminolevulinic acid for fluorescenceguided resection of recurrent malignant gliomas: a phase II study. Neurosurgery 65:1070-1077, 2009

47. Nakagawa M, Matsumoto K, Higashi H, Furuta T, Ohmoto T: Acute effects of interstitial hyperthermia on normal monkey brain-magnetic resonance imaging appearance and effects on blood-brain barrier. Neurol Med Chir (Tokyo) 34:668675,1994

48. Niranjan A, Kondziolka D: Experimental radiosurgery models, in Chin LS, Regine WF (eds): Principles and Practice of Stereotactic Radiosurgery. New York: Springer, 2008, pp 61-67

49. Norred SE, Johnson JA: Magnetic resonance-guided laser induced thermal therapy for glioblastoma multiforme: a review. Biomed Res Int 2014:761312, 2014

50. Noushmehr H, Weisenberger DJ, Diefes K, Phillips HS, Pujara $\mathrm{K}$, Berman $\mathrm{BP}$, et al: Identification of a $\mathrm{CpG}$ island methylator phenotype that defines a distinct subgroup of glioma. Cancer Cell 17:510-522, 2010

51. Ohgaki H, Dessen P, Jourde B, Horstmann S, Nishikawa T, Di Patre PL, et al: Genetic pathways to glioblastoma: a population-based study. Cancer Res 64:6892-6899, 2004

52. Omuro A, DeAngelis LM: Glioblastoma and other malignant gliomas: a clinical review. JAMA 310:1842-1850, 2013

53. Ostrom QT, Gittleman H, Farah P, Ondracek A, Chen Y, Wolinsky Y, et al: CBTRUS statistical report: Primary brain and central nervous system tumors diagnosed in the United States in 2006-2010. Neuro Oncol 15 (Suppl 2):ii1-ii56, 2013

54. Oztaş B, Küçük M: Reversible blood-brain barrier dysfunc- tion after intracarotid hyperthermic saline infusion. Int J Hyperthermia 14:395-401, 1998

55. Park JK, Hodges T, Arko L, Shen M, Dello Iacono D, McNabb A, et al: Scale to predict survival after surgery for recurrent glioblastoma multiforme. J Clin Oncol 28:3838-3843, 2010

56. Perry JR, Bélanger K, Mason WP, Fulton D, Kavan P, Easaw J, et al: Phase II trial of continuous dose-intense temozolomide in recurrent malignant glioma: RESCUE study. J Clin Oncol 28:2051-2057, 2010

57. Rahmathulla G, Recinos PF, Kamian K, Mohammadi AM, Ahluwalia MS, Barnett GH: MRI-guided laser interstitial thermal therapy in neuro-oncology: a review of its current clinical applications. Oncology 87:67-82, 2014

58. Reimer P, Bremer C, Horch C, Morgenroth C, Allkemper T, Schuierer G: MR-monitored LITT as a palliative concept in patients with high grade gliomas: preliminary clinical experience. J Magn Reson Imaging 8:240-244, 1998

59. Sabel M, Rommel F, Kondakci M, Gorol M, Willers R, Bilzer T: Locoregional opening of the rodent blood-brain barrier for paclitaxel using Nd:YAG laser-induced thermo therapy: a new concept of adjuvant glioma therapy? Lasers Surg Med 33:75-80, 2003

60. Sakai T, Fujishima I, Sugiyama K, Ryu H, Uemura K: Interstitial laserthermia in neurosurgery. J Clin Laser Med Surg 10:37-40, 1992

61. Schneider JP, Trantakis C, Rubach M, Schulz T, Dietrich J, Winkler D, et al: Intraoperative MRI to guide the resection of primary supratentorial glioblastoma multiforme-a quantitative radiological analysis. Neuroradiology 47:489-500, 2005

62. Schulze PC, Vitzthum HE, Goldammer A, Schneider JP, Schober R: Laser-induced thermotherapy of neoplastic lesions in the brain-underlying tissue alterations, MRI-monitoring and clinical applicability. Acta Neurochir (Wien) 146:803812,2004

63. Schwabe B, Kahn T, Harth T, Ulrich F, Schwarzmaier HJ: Laser-induced thermal lesions in the human brain: short- and long-term appearance on MRI. J Comput Assist Tomogr 21: 818-825, 1997

64. Schwarzmaier HJ, Eickmeyer F, von Tempelhoff W, Fiedler VU, Niehoff H, Ulrich SD, et al: MR-guided laser irradiation of recurrent glioblastomas. J Magn Reson Imaging 22:799803,2005

65. Schwarzmaier HJ, Eickmeyer F, von Tempelhoff W, Fiedler VU, Niehoff H, Ulrich SD, et al: MR-guided laser-induced interstitial thermotherapy of recurrent glioblastoma multiforme: preliminary results in 16 patients. Eur J Radiol 59:208-215, 2006

66. Senft C, Franz K, Blasel S, Oszvald A, Rathert J, Seifert V, et al: Influence of iMRI-guidance on the extent of resection and survival of patients with glioblastoma multiforme. Technol Cancer Res Treat 9:339-346, 2010

67. Sloan AE, Ahluwalia MS, Valerio-Pascua J, Manjila S, Torchia MG, Jones SE, et al: Results of the NeuroBlate System first-in-humans Phase I clinical trial for recurrent glioblastoma. Clinical article. J Neurosurg 118:1202-1219, 2013

68. Sonntag PD, Hinshaw JL, Lubner MG, Brace CL, Lee FT Jr: Thermal ablation of lung tumors. Surg Oncol Clin N Am 20: 369-387, ix, 2011

69. Souhami L, Seiferheld W, Brachman D, Podgorsak EB, Werner-Wasik M, Lustig R, et al: Randomized comparison of stereotactic radiosurgery followed by conventional radiotherapy with carmustine to conventional radiotherapy with carmustine for patients with glioblastoma multiforme: report of Radiation Therapy Oncology Group 93-05 protocol. Int J Radiat Oncol Biol Phys 60:853-860, 2004

70. Stummer W, Nestler U, Stockhammer F, Krex D, Kern BC, Mehdorn HM, et al: Favorable outcome in the elderly cohort treated by concomitant temozolomide radiochemotherapy in a multicentric phase II safety study of 5-ALA. J Neurooncol 103:361-370, 2011 


\section{Laser ablation for gliomas}

71. Stummer W, Pichlmeier U, Meinel T, Wiestler OD, Zanella F, Reulen HJ: Fluorescence-guided surgery with 5-aminolevulinic acid for resection of malignant glioma: a randomised controlled multicentre phase III trial. Lancet Oncol 7:392401, 2006

72. Stupp R, Mason WP, van den Bent MJ, Weller M, Fisher B, Taphoorn MJ, et al: Radiotherapy plus concomitant and adjuvant temozolomide for glioblastoma. N Engl J Med 352:987-996, 2005

73. Sugiyama K, Sakai T, Fujishima I, Ryu H, Uemura K, Yokoyama T: Stereotactic interstitial laser-hyperthermia using Nd-YAG laser. Stereotact Funct Neurosurg 54-55:501-505, 1990

74. Vaccaro AR, Eck JC: Introduction to best evidence medicine, in Quiñones-Hinojosa A, Raza SM (eds): Controversies in Neuro-Oncology: Best Evidence Medicine for Brain Tumor Surgery. New York: Thieme, 2014, pp 1-8

75. Vredenburgh JJ, Desjardins A, Herndon JE II, Marcello J, Reardon DA, Quinn JA, et al: Bevacizumab plus irinotecan in recurrent glioblastoma multiforme. J Clin Oncol 25:47224729, 2007

76. Walbert T, Mikkelsen T: Recurrent high-grade glioma: a diagnostic and therapeutic challenge. Expert Rev Neurother 11:509-518, 2011

77. Wen PY, Kesari S: Malignant gliomas in adults. N Engl J Med 359:492-507, 2008

78. Westphal M, Hilt DC, Bortey E, Delavault P, Olivares R, Warnke PC, et al: A phase 3 trial of local chemotherapy with biodegradable carmustine (BCNU) wafers (Gliadel wafers) in patients with primary malignant glioma. Neuro Oncol 5:79-88, 2003

79. Westphal M, Ram Z, Riddle V, Hilt D, Bortey E: Gliadel wafer in initial surgery for malignant glioma: long-term followup of a multicenter controlled trial. Acta Neurochir (Wien) 148:269-275, 2006

80. Wick A, Pascher C, Wick W, Jauch T, Weller M, Bogdahn U, et al: Rechallenge with temozolomide in patients with recurrent gliomas. J Neurol 256:734-741, 2009

81. Wolf DS, Laterra J: Salvage therapy for high-grade gliomas, in Quiñones-Hinojosa A, Raza SM (eds): Controversies in Neuro-Oncology: Best Evidence Medicine for Brain Tumor Surgery. New York: Thieme, 2014, pp 97-106

82. Wong ET, Gautam S, Malchow C, Lun M, Pan E, Brem S: Bevacizumab for recurrent glioblastoma multiforme: a metaanalysis. J Natl Compr Canc Netw 9:403-407, 2011

Manuscript submitted August 6, 2014.

Accepted September 16, 2014.

Please include this information when citing this paper: DOI: 10.3171/2014.9.FOCUS14471.

Address correspondence to: Eric C. Leuthardt, M.D., Washington University School of Medicine, Department of Neurological Surgery, 660 S. Euclid Ave., Campus Box 8057, St. Louis, MO 63110. email: leuthardte@wudosis.wustl.edu. 